\title{
TERCEIRO SETOR a organização das políticas sociais e a nova esfera pública
}

JosÉ RoGÉRIO LOPES

\begin{abstract}
Resumo: A forma como vem se configurando o "Terceiro Setor", no Brasil, indica a presença de agentes políticos, culturais, econômicos e sociais, com ações nem sempre convergentes para a criação de modelos dinâmicos de organização. No campo das políticas sociais, visualiza-se hiato entre o conjunto de carências e a emergência de novo papel da sociedade civil, com base em pesquisas do autor no Vale do Paraíba. Palavras-chave: terceiro setor; administração pública; organização social.
\end{abstract}

Abstract: The Third Sector in Brazil brings together political, cultural, economical and social agents through actions not always focused to create dynamic patterns of organization. In the field of social politics there is a gap between the people needs and the new society role, according to the author's research in Vale do Paraíba. Key words: third sector; public administration; social organization.

Nos anos 90, importa menos a presença de movimentos sociais como estruturas especificas, e importam mais as novas instituições, os novos quadros de pessoal, a nova mentalidade sobre a coisa pública; em suma, importa mais a nova cultura política gerada.

Maria da Glória Gohn (2000, p. 51)

A epígrafe refere-se à conclusão a que a autora chega, na análise do cenário brasileiro de lutas sociais na era da globalização. Os termos colocados em evidência nessa citação servirão como ponto de partida para decodificarmos o significado das relações propostas no título deste texto.

Vale ressaltar desde já que esta reflexão atenta aos princípios que transcendem as práticas sociais das ONGs, que vêm sendo amplamente analisadas, buscando situar sua importância em um conjunto mais amplo de referências, sugerindo que elas compõem somente um dos termos pre- sentes na configuração de novas esferas públicas da sociedade brasileira.

Desta feita, desdobrar-se-ão alguns questionamentos sobre as imbricações entre tais esferas públicas, considerando-se que a concepção de ONG aqui em discussão segue a tipologia definida por Gohn (2000). Analisam-se, principalmente, as relações entre o poder público municipal e as ONGs, com as quais este desenvolve suas ações, na efetivação de políticas públicas.

\section{DECODIFICANDO OS TERMOS}

A relação entre o Estado e as ONGs, no plano da administração "pública", remete necessariamente ao princípio, ao planejamento e à execução da gestão das políticas sociais públicas - refere-se, aqui, ao campo específico das ações das "ONGs cidadãs", não das ONGs assistencialis- 
tas ou desenvolvimentistas, como as denomina Gohn (2000, p. 53-64). Entretanto, expor reflexões sobre a gestão das políticas sociais não é tão simples quanto se pensa, mesmo para aqueles que se dedicam ao exercício da investigação sobre a questão social ou ao exercício das ações de governo.

As demandas sociais da população e as ações de governo em resposta geralmente são mediadas por procedimentos que possuem significados desconhecidos ou inconscientes para muitas pessoas, a começar pelo que se entende como público, gestão e política social. Primeiramente, então, buscam-se as definições: o que é a coisa pública? O que é gestão? O que é política social?

Segundo os significados grafados no Dicionário brasileiro de língua portuguesa, do Jornal da Tarde:

Público, adj. Relativo ou pertencente ao povo; que pertence ou se refere à massa geral dos habitantes de uma localidade; popular; comum; que serve para uso de todos; [...] fonte pública; relativo à governação de um país; conhecido de todos; notório; vulgar; a que todos podem assistir; [...] (Do lat. publicu).

Noção regularmente encontrada em outros dicionários acessíveis à população, o termo "público" significa a esfera de fatos, relações e recursos que pertencem ou se referem aos habitantes de uma localidade, no sentido de que lhes interessam e servem à efetivação da organização do seu princípio de governo. Nesse sentido, "coisa pública" é todo fato, recurso e relação que tem sua origem na "fonte pública" e se direciona para configurar a governação de um município, estado ou país.

"Gestão, s.f. Ato de gerir; gerência; administração; direção. Do latim gestione". Quando se buscam outros significados, encontra-se: "Gerir, v. tr. dir. Administrar; dirigir; governar. (Conjuga-se como o verbo aderir.) (Do latim gerere)" (DICIONÁRIO BRASILEIRO DA LÍNGUA PORTUGUESA, DO JORNAL DA TARDE). Vê-se, aqui, que os significados das palavras desdobram-se nos termos informativos que os descrevem. Em princípio, não há eqüidade de um termo para outro, senão quando mecanicamente articulados. O significado da palavra é ideológico, tanto quanto a ação que corresponde à sua idéia.

Para tornar essa concepção mais problemática, diz o Moderno dicionário da língua portuguesa Michaelis: "Gestão, s.f. (lat. gestione) 1. Ato de gerir. 2. Administração, direção. G. de negócio: administração oficiosa de negócio alheio, feita sem preocupação". Por que sem preocupação? É o Novo dicionário da língua portuguesa, de
Aurélio Buarque de Holanda Ferreira, que explica: "Gestão [Do lat. gestione] s.f. Ato de gerir; gerência, administração. Gestão de negócios. Jur. Administração oficiosa de negócio alheio, sem mandato ou representação legal". Em contrapartida, segundo Pereira (1998, p. 60-61, grifos meus),

quando falamos de política social, estamos nos referindo àquelas funções modernas do Estado capitalista - imbricado à sociedade - de produzir, instituir e distribuir bens e serviços sociais categorizados como direitos de cidadania. Trata-se, portanto, de política associada a um padrão de organização social e política que, desde os fins do século XIX e, mais precisamente, depois da Segunda Guerra Mundial, foi distanciando-se dos parâmetros do laissezfaire e do legado das velhas leis contra a pobreza [...] para transformar-se num esquema de proteção social que incumbe ao Estado decisiva responsabilidade pelo bemestar dos cidadãos. [...] [Ela] envolve o processo de provisão social [...][e] uma expressiva atividade regulamentadora [que visa] a garantia de acesso do cidadão comum a benefícios e serviços de natureza pública.

Agora, averigua-se que articulações podem ser feitas entre os termos do enunciado: "O princípio de gestão e a construção da esfera pública”.

\section{AFINANDO A IDÉIA OU REARTICULANDO OS TERMOS}

A gestão das políticas sociais pode ser pensada segundo dois princípios orientadores - elaborados aqui como "tipos ideais" -, conforme estejam articulados em torno dos sentidos que originam o substantivo gestão e o verbo gerir. Isso não significa, necessariamente, uma divisão entre teoria e prática, mas sobretudo uma distinção entre métodos de gestão, ou seja, substantivamente, a gestão é administração e direção da coisa pública; no sentido verbal, é governar e aderir à coisa pública. Tais princípios são complementares e procura-se mostrar que alguns governos optam somente pelo tipo substantivo de gestão.

Para tanto, pode-se começar perguntando: administrar e dirigir o quê? Governar para quê? Aderir a quê?

$\mathrm{Na}$ medida em que a política social, no sentido aqui definido, implica uma "política associada a um padrão de organização social e política", deve-se entender que essa associação se configura como o efeito contraditório de uma intervenção político-econômica sobre a sociedade, para implantação de um modelo de desenvolvimento que or- 
dene a organização social e política. A política social é, assim, a contraface do próprio modelo de desenvolvimento, agindo sobre os efeitos negativos gerados em sua implantação e manutenção.

Se há uma contradição de fundo na própria necessidade de gerir uma política social associada a um modelo de desenvolvimento, é porque se constata que a intervenção político-econômica que o sustenta não é extensivamente dirigida a todos, ao menos positivamente. Políticas sociais só existem, dessa forma, em sociedades que reconhecem as desigualdades geradas pelo seu modelo de desenvolvimento e só são implantadas por governos comprometidos (ou pressionados pela população) com a diminuição ou com a superação dessas desigualdades. "Política social, assim identificada, integra um complexo político-institucional denominado seguridade social" (PEREIRA, 1998, p. 61) e configura o que conhecemos como Estado de bem-estar social.

Nas palavras de Sposati (1999, p. 10),

as politicas sociais revelam o empenho de uma sociedade em afirmar um patamar de civilidade. Por que civilidade? Porque demonstra o que esta sociedade vem assegurando para todos os seus cidadãos. Nós conhecemos o padrão de civilidade de uma sociedade pelo que ela faz, o que ela propõe para as suas crianças e seus velhos. Em outras palavras, como esta sociedade no presente se relaciona com a história, o passado e o futuro. Então, quando discutimos política social, temos que sair dessa visão corriqueira de só olhar qual é o programa, o que está sendo feito imediatamente, mas entender que por trás daquela ação está em questão um padrão de civilidade que esta sociedade está construindo. Por que civilidade? Por conta de um respeito à dignidade humana, por conta de assegurar um dado padrão de dignidade humana ao coletivo de cidadãos de uma sociedade.

Não é à toa que o governo $\mathrm{FHC}$, dessa forma, convergia suas ações para procedimentos político-econômicos e não para uma política social: a ausência desta encobre o reconhecimento efetivo dos efeitos desiguais e contraditórios de sua intervenção político-econômica. No mesmo sentido, quando governos estaduais e municipais de base democrática e popular, comprometidos com as demandas de suas populações, investem em política social e mostram quantitativa e qualitativamente os procedimentos de exclusão social gerados por aquela intervenção, são taxados de ineficazes. Quando se endividam para cumprir seus compromissos, são taxados de caloteiros. Ou seja, quando os governos agem segundo a opção de "governar aderindo à satisfação das necessidades públicas", são acusa- dos de tramarem contra o modelo de desenvolvimento.

Outra forma de eximir-se dessas contradições é privatizar o patrimônio público, sob a alegação de dar nova orientação ao Estado, tornando-o eficiente no que é sua obrigação. Opção coerente com o primeiro princípio de gestão anteriormente descrito, essa argumentação esconde um fato de peso relevante: o Estado compõe, com a sociedade civil, a esfera pública. Diminuir a presença do Estado é diminuir seu peso na definição das necessidades sociais. Embora essa estratégia dê a impressão de maior autonomia da sociedade civil na determinação de suas necessidades sociais, o que ocorre efetivamente é que o Estado busca estabelecer, cada vez mais, sua função regulamentadora, o exercício de administrar e dirigir, mas se exime progressivamente da provisão social, de garantir "o acesso do cidadão comum a benefícios e serviços de natureza pública", que é governar e aderir.

Conforme já mostraram Lessa et al. (1997, p. 83-84),

em alguns campos da política social, a questão não é sequer a de falta de recursos. No caso dos programas de habitação e saneamento, por exemplo, a necessidade de redefinir modelos institucionais e estratégias de financiamento justificou a retração do gasto federal do governo FHC, nesses programas literalmente paralisados no governo Collor. Pode-se dizer que, até aqui, foram os governos locais os responsáveis pelos investimentos neles realizados, com o aporte de financiamentos externos de instituições multilaterais, como BID e Bird.

Temos, então, no Brasil, um governo federal que opta pelo primeiro tipo de gestão e que procura impor por ele não uma política social, mas um modelo de desenvolvimento dirigido preferencialmente por intervenções políticoeconômicas. Em compensação - e aí deve-se proceder a um inventário mais rigoroso -, há vários governos estaduais e municipais que rompem com essa direção, apontando para outro modelo de desenvolvimento, aderindo às necessidades públicas e governando segundo interesses democráticos e populares. Logo, constata-se não haver uma gestão de política social no país, mas gestões de políticas sociais. Da mesma forma, não existe uma esfera pública instituída, mas subesferas localizadas e instituintes.

\section{A GESTÃO DAS POLÍTICAS SOCIAIS EM ESFERAS PÚBLICAS INSTITUINTES: AS ONGS}

Este é o cerne da questão: gerir políticas sociais é mais que governar e satisfazer as necessidades públicas, pois é 
também aderir ao projeto de instituição de uma esfera pública. Esse objetivo é central, sob pena de confundir até mesmo o que são as necessidades públicas, ou de relativizá-las sob perspectivas ideológicas distintas. ${ }^{1}$

A constituição da esfera pública é parte integrante do processo de democratização da vida social, pela via do fortalecimento do Estado e da sociedade civil, de forma a inscrever os interesses das maiorias nos processos de decisão política. É um movimento que pretende conferir níveis crescentes de publicização no âmbito da sociedade política e da sociedade civil, no sentido da criação de uma nova ordem democrática valorizadora da universalização dos direitos de cidadania. [...] Os caminhos de formação dessa esfera comum são construídos pelo discurso e pela ação dos sujeitos sociais que, estabelecendo uma interlocução pública, possam deliberar em conjunto as questões que dizem respeito a um destino coletivo (RAICHELIS, 1998, p. 78, grifos meus).

Dentro desse conceito, uma esfera pública se estabelece nos fóruns coletivos, cujas deliberações definirão gradualmente sua instituição. Tais decisões resultam da interlocução entre segmentos da população local preocupados com as problemáticas sociais que dizem respeito às necessidades públicas. E essa interlocução deve se consolidar num movimento de continuidade e de expansão. Por quê? Porque a trajetória das políticas sociais no Brasil é diferenciada: a saúde, a previdência e a assistência social, por exemplo, possuem trajetórias históricas diferentes e, embora elas componham o tripé da Seguridade Social, segundo a Constituição de 1988, ainda não estão suficientemente agregadas. Torna-se necessário, dessa forma, articular tais políticas em torno de esferas públicas ampliadas para além de encontros, fóruns e conferências setorizados.

Essa articulação deve promover um modelo de organização de segmentos participativos da sociedade que implique uma nova configuração das políticas sociais, capaz de produzir estratégias amplas de enfrentamento da exclusão social, de forma a inscrever os interesses das maiorias nos processos de decisão política. Ocorre que, no movimento contemporâneo de ampliação da esfera pública, proliferam presenças diversificadas de agentes políticos, culturais, econômicos e sociais, com ações ou discursos nem sempre convergentes na criação de modelos dinâmicos de organização. Assim, o estabelecimento da interlocução pública nem sempre se direciona para possibilidades de deliberação em conjunto das questões que dizem respeito a um destino coletivo.
Na medida em que tais presenças têm adquirido uma visibilidade diferenciada na sociedade, pela ação de diversos fatores, torna-se necessária uma pequena revisão de suas projeções, de forma a compreender alguns aspectos da formação dessa nova esfera pública.

Inicialmente, há um duplo registro histórico a enfatizar: de um lado, o deslocamento progressivo da "luta de classes" da esfera das relações capital versus trabalho para a esfera do fundo público (OLIVEIRA, 1998), provocado pela crescente metamorfose da sociedade do salariado (CASTEL, 1997); de outro, a passagem das manifestações coletivas de caráter amplo, organizadas nos movimentos sociais reivindicatórios (como entre a década de 60 e meados da de 80), para as manifestações estruturadas em ações coletivas combinadas em organizações sociais instituídas, de caráter restrito, que se expandiram de meados da década de 80 até a de 90 (GOHN, 2000).

Esse registro histórico permite supor que um critério para estabelecer as projeções das presenças de sujeitos, categorias e segmentos sociais em interlocução pode ser o "pluralismo" das manifestações e reivindicações expressas pelos mesmos na contemporaneidade. Vejamos alguns exemplos.

Um elemento característico das esferas públicas instituintes tem sido identificado nas ONGs. Ocorre que esta esfera não é tão pública como parece, à primeira vista, visto que as ONGs se articulam em torno de interesses públicos, mas regularmente se constituem em uma esfera privada, visando gerir necessidades públicas específicas ou atuar sobre elas utilizando recursos advindos geralmente da fonte pública. É o que ocorre em São José dos Campos e Taubaté, municípios situados na região do Vale do Paraíba (SP), onde as receitas das ONGs advêm prioritariamente do fundo público. Trata-se de uma administração oficiosa de negócios públicos, sem mandato ou representação legal definidos na esfera pública.

À diferença dos sindicatos, das associações de moradores ou mesmo dos movimentos sociais, as ONGs não podem falar ou agir em nome de terceiros. Fazem-no somente em nome próprio (FERNANDES, 1996).

A essa forma de administrar o negócio público, Vieira (1999, p. 24) tem denominado

terceiro setor organizacional, ele é apenas terceiro setor do ponto de vista organizativo, ele não é uma propriedade. Por que não é uma propriedade? Porque os recursos públicos são recursos vindos de taxas e 
impostos, são recursos que vêm daquilo que chamamos de subsídios e, portanto, eles saem do tesouro e do orçamento da nação. Então não é um terceiro setor não estatal, ele é um terceiro setor público organizacional, não uma propriedade nova que foi criada, já que os subsídios são públicos, é o setor incentivado.

A posição de Vieira polemiza com outras posições otimistas, que vêem na emergência do Terceiro Setor uma abertura dos canais de decisão à participação da sociedade civil. Sem enfatizar a origem do suporte financeiro de manutenção das ONGs, o discurso dos apologistas do Terceiro Setor tem geralmente recaído numa argumentação que desqualifica o Estado como esfera de efetivação das políticas sociais e públicas. Tal argumentação, visando sobretudo realçar o papel e a importância das ONGs, muitas vezes obscurece o fato de que muitas delas não definiram sua posição no confronto entre os projetos sociais hoje em pauta, no campo das políticas sociais.

Dessa maneira, não se trata efetivamente de um campo instituído, ou de uma esfera pública instituinte, mas de "formações culturais" constituídas por uma associação de sujeitos, como definido por Wiliams (1992), que se identificam por "seu foco de missão". ${ }^{2}$

Essa idéia sugere que há uma teleologia operativa estruturada em tais "formações culturais", que ganha visibilidade sobretudo nas propostas de "atividades sociais" que as ONGs assistencialistas e desenvolvimentistas geralmente desenvolvem. Tais atividades sociais podem ser definidas como "atividades que estimulam, reforçam, influenciam ou direcionam práticas de sociabilidade", caracterizadas por um fundo ideológico-político diversificado.

Nas pesquisas realizadas na região do Vale do Paraíba, ${ }^{3}$ por exemplo, constatou-se que: as ONGs assistencialistas e desenvolvimentistas realizam uma variedade de ações profissionalizantes tradicionais e artesanais ou manuais, mas poucas delas proporcionam geração de recursos financeiros aos usuários; regularmente, estes não participam da gestão das ONGs ou, quando o fazem, estão limitados a um dos procedimentos, como planejamento, execução, acompanhamento ou avaliação de atividades; os trabalhos geralmente reproduzem estruturas diferenciadoras das relações sociais de gênero; a divulgação das ações das ONGs é realizada de forma restrita, direcionada a seus próprios usuários e participantes; a maioria das ONGs avalia seus trabalhos com reuniões; nenhuma organização pretende manter a sociedade do jeito que está, propondo idealizações de melhoria, porém justificadas pelas restrições que as próprias enfrentam na efetivação de suas atividades.

$\mathrm{Na}$ maioria dos casos pesquisados, as ONGs realizam atividades mínimas de manutenção, recorrentes a um modelo de atuação com a pobreza reproduzido desde os programas estatais. Assim, mais de 50\% dos usuários atendidos nas ONGs estão na faixa de renda familiar de menos de 1 salário mínimo, enquanto os demais recebem de 1 a 6 salários mínimos. Aqui, surge uma hipótese interessante: a proximidade das faixas de renda dos usuários atendidos, abaixo e acima de 1 salário mínimo, pode significar que as organizações direcionam suas atividades predominantemente para os sujeitos que estão abaixo da linha da pobreza, mas também para aqueles que vivenciam o processo de empobrecimento ou precarização das condições de via.

Os critérios para separar tais usuários por classes distintas estão sendo definidos pelos serviços ou atendimentos prestados aos mesmos pelas ONGs. Se a hipótese for verdadeira, os tipos de serviços ou atendimentos devem ser semelhantes, conforme as classes de renda se aproximem, frente a essa linha de corte (os extremos das faixas de renda atendidas). Caso se confirme tal hipótese, podese supor que as organizações estão se tornando a porta de entrada dos sujeitos que empobrecem aos serviços e bens públicos de manutenção de suas necessidades básicas, o que abre oportunidade para uma série de questionamentos derivados.

Já as atividades das ONGs cidadãs também se direcionam para a estruturação de práticas de sociabilidade, mas com uma dimensão ideológica, ética e política distinta. Aqui, são expostos sucintamente três casos acompanhados, visando analisar como se opera a interlocução entre as organizações, o poder público e a sociedade civil para a ampliação da esfera pública.

O primeiro caso é o de uma ONG de ambientalistas de Taubaté, município da região do Vale do Paraíba que vem recebendo muitos investimentos privados na última década, com a instalação de indústrias. O crescimento da atividade produtiva gerou desdobramentos diversos que obrigaram a prefeitura local a realizar reformas urbanísticas em várias regiões da cidade. Essa necessidade relacionase com a ONG estudada, que tem sede e estrutura de funcionamento garantidas pela Prefeitura local há vários anos. Suas ações resumiam-se, até 1994, a campanhas de informação sobre problemas ambientais da região e de mobilização para a recuperação de áreas degradadas. Após essa 
data, a ONG passou a denunciar problemas ambientais causados por toda ordem de situações, desde a instalação de indústrias até a ação de portos de areia na região.

Recentemente, um agente dessa ONG fez uma denúncia ao Ibama contra a Prefeitura de Taubaté, pela canalização do córrego Convento Velho, cujo curso corta o município e pelo lançamento de esgoto domiciliar nele. A obra foi embargada e a ONG foi ameaçada pelo governo local de ter sua sede desativada e de cortes nos recursos repassados pelo município.

Após discutirem sobre o acontecido, os agentes da ONG assumiram posturas diferenciadas sobre o objeto da denúncia. $\mathrm{O}$ agente denunciante (um agrônomo) defendia que o curso do córrego, na cidade, deveria ter suas matas ciliares preservadas, pois se trata de uma questão ambiental; outro agente (agrônomo e professor universitário) defende que o córrego já está poluído demais e que, portanto, pode ser canalizado. Este último argumenta que a canalização do córrego não deve ser tratada como questão ambiental - justificando que "o problema passa a ser o da vazão da água do córrego (em caso de enchentes urbanas) e da poluição, requerendo ações mitigadoras e compensatórias" - mas paisagística e que as obras de esgoto são de responsabilidade da Sabesp, não da prefeitura.

O debate que sucedeu o evento da denúncia tornou-se técnico e restrito ao âmbito da ONG, gerando poucos esclarecimentos públicos, enquanto a obra permanece embargada pelo Ibama.

Os outros dois casos vêm de Campos do Jordão, município situado na Serra da Mantiqueira, entre o Vale do Paraíba e o sul de Minas Gerais. Conhecida como a "Suíça Brasileira", o município apresenta problemas ambientais e urbanísticos sérios devido a sua localização, como, por exemplo, a captação de água para abastecimento da população, o destino do lixo, a ocupação irregular de áreas de proteção ambiental e a expansão de periferias e favelas, causada pelo aumento da migração. Nesse contexto, duas ONGs vêm se destacando recentemente.

A primeira é uma ONG de ambientalistas, formada por vários agentes de classe média da cidade, como empresários, professores, profissionais liberais, entre outros, e que tem como principal meta, atualmente, a preservação do Ribeirão Capivari, principal recurso de captação de água para a cidade. Sua estratégia foi primeiramente realizar uma campanha ampla de comunicação, de caráter informativo e educativo, que inclui cartazes, cartilhas e vinhetas em uma rede de emissoras de rádio da região. Tal campa- nha iniciou-se em janeiro de 2001, com depoimentos de agentes locais e esclarecimentos sobre a importância do Ribeirão para o município e foi, progressivamente, incorporando depoimentos de agentes regionais, estaduais e nacionais, de agências e órgãos dedicados à questão ambiental, em instâncias governamentais ou fora delas, e esclarecimentos sobre a problemática contemporânea dos recursos hídricos, que chegou a incluir o problema do racionamento de energia elétrica no país. ${ }^{4}$

Em outro momento, com a ampliação e diversificação da campanha, a ONG passou a buscar recursos financeiros para a elaboração de projetos de recuperação e preservação do Ribeirão Capivari, solicitando apoio institucional aos agentes mais destacados que participaram da campanha, sobretudo nas instâncias de governo estadual e federal e aos empresários que possuem residências no município.

A intenção da ONG, entretanto, não é a de realizar os projetos, mas entregá-los à prefeitura local para que ela os realize, ficando em uma condição de parceira no planejamento e no controle, mas não na execução dos serviços necessários.

A segunda ONG em destaque é uma associação civil formada basicamente por pessoas que possuem propriedades no município, mas residem na capital paulista. São empresários ou profissionais liberais de sucesso, que se deslocam para Campos do Jordão para férias de inverno ou viagens ocasionais de lazer.

Essa ONG foi criada com a finalidade de propor e elaborar projetos de melhorias para o município, tendo em vista seus problemas. Nesse sentido, seus agentes apresentaram uma proposta de elaboração gratuita do Plano Diretor do município, o que vem sendo muito discutido nas instâncias de governo e entre segmentos da sociedade local, mas que já foi aceita pelo prefeito atual, que também é empresário.

Antes mesmo de a proposta ser implantada, surgiu uma questão de fundo: como conjugar nesse Plano Diretor os interesses dos proprietários/investidores com as diretrizes de desenvolvimento social necessárias ao município? A resposta veio com um problema prático que se instalou no desenvolvimento dos debates em torno da proposta. Em uma matéria sobre problemas de infra-estrutura na região, publicada no jornal Folha de S.Paulo (29/04/2001, p. C3), o assessor técnico do gabinete da prefeitura foi questionado sobre a reivindicação da população pobre residente em algumas áreas periféricas do município, que solicitava do prefeito o asfaltamento do acesso a seus bairros, ao 
que respondeu: "Há turistas que não querem nem asfalto nem iluminação. Dizem que isso acabaria com a beleza natural de Campos".

Ora, para um município com um contingente de pobreza alto, que "tem somente $30 \%$ de suas ruas asfaltadas ou calçadas e 20\% delas iluminadas" (FOLHA DE S.PAULO, 29/04/2001, p. C3), a noção de preservação da beleza natural da cidade, expressa por esses turistas, é no mínimo segregadora.

Vê-se então, em tais casos descritos, que alguns aspectos apresentam referências comuns:

- os agenciamentos das ONGs explicitam dimensões diversificadas da questão social contemporânea, exteriorizando problemas muitas vezes velados nas relações entre o Estado e a sociedade civil, o que é característica do seu exercício emergente de mediação nessas relações de organização social;

- seus agenciamentos também sugerem um distanciamento entre o saber necessário (que as organizações possuiriam) para a resolução dos problemas dos municípios e a capacidade para tanto explicitada pelos governos locais;

- aos governos locais é reconhecida, entretanto, a capacidade de execução dos projetos elaborados e agenciados pelas ONGs;

- as instâncias de governo são caracterizadas, também, como fontes de financiamento (na forma dos fundos públicos) ou de intermediação para manutenção das ONGs e de seus projetos;

- a informação da população, visando a manifestação da opinião pública, é vista ora como recurso estratégico para captação de investimentos ou para sustentação política, pois agrega valor às ações das ONGs, ora como depositária de discussões técnicas ou econômicas restritas, com pouca repercussão na formação de uma esfera pública efetiva.

No conjunto de tais referências, duas possibilidades se configuram: de um lado, os problemas

propostos pela experiência [das ONGs] contribuem para tornar retrátil a ação e cada vez mais manifesta a intenção: assim o ator social se convence até mesmo do ainda-nãoverdadeiro ou do quase-falso que constituem os ordenamentos conjeturais do conhecimento (CAMPA, 1985, p. 15);

de outro, as ações das ONGs reproduzem modelos em que

as variáveis independentes da ação são computadas estatisticamente nos resultados da própria ação: qualquer coi- sa pode ser justificada se não se esboçam forças capazes de contrastá-la. De fato, entende-se o todo como aquele momento magmático e indiferencial a que são congênitas a adesão, a filiação virtual de todos, sem que a consciência da totalidade ou da maioria dos componentes comunitários se explicite ou se manifeste (CAMPA, 1985, p. 14).

De qualquer forma, a presença marcante das ONGs reforça a concepção de García-Pelayo (1977, p. 25), de que

Estado e sociedade não são mais sistemas autônomos, autoregulados, unidos por um número limitado de relações, $e$ que recebem ou enviam impulsos e produtos definidos, mas antes dois sistemas fortemente inter-relacionados entre si através de relações complexas, com fatores de regulação que se encontram fora dos respectivos sistemas e com um conjunto de subsistemas interseccionados, de que dão prova o cumprimento de funções estatais através de empresas de constituição jurídica privada, a realização de importantes funções públicas por meio de contratos, a presença de representantes do setor privado nas comissões estatais e nos centros de decisão.

Se a presença difusa de diversos agentes coloca em cena necessidades e expectativas concretas definidas nos termos de "exercício de liberdade", como as configuradas nas ONGs, em contrapartida provoca-se uma crise de regulação das "garantias formais que [...] constituem as précondições lógicas para a mudança efetiva das relações intersubjetivas" (GARCÍA-PELAYO, 1977, p. 19).

Dessa forma, reconhecendo o escopo restrito e focalizado dessa análise, é necessário inventariar os tipos de ONGs que emergem e suas articulações em torno de um projeto social, para configurar o caráter instituinte de esfera pública que se enforma entre as organizações e em suas relações com a sociedade civil e o Estado.

Um bom critério para começar consiste na identificação do alinhamento das finalidades das ONGs com o "Plano de Reforma do Estado" proposto pelo governo federal, como também na investigação e análise das diversas ações e dos projetos em desenvolvimento das ONGs, nas três instâncias de governo. Deve-se avaliar se tais ações realmente aderem às necessidades públicas ou se reproduzem demandas de grupos e segmentos restritos, organizados em torno da captação dos recursos públicos e da defesa de seus interesses.

Essa avaliação torna-se necessária porque, pela mediação das ONGs, 
enquanto a sociedade civil perde a capacidade de autoregulação, o Estado não adquire nesse mesmo contexto a legitimação de sua intervenção. De fato, a desautorização do Estado depende da crise do saber, da extrema relatividade do conhecimento que, em niveis complementares e portanto potencialmente conflituais, determina processos produtivos de grande monta [...]. Uma confluência de interesses, gerada por uma co-participação criativa caótica, determina a complexidade das decisões investidas de poder (CAMPA, 1985, p. 18).

E aqui, sem desconsiderar a importância que as ações de várias ONGs vêm mostrando no cenário contemporâneo, devemos reconhecer que o aumento gradativo do número de organizações, sobretudo em âmbito local, não tem correspondido às expectativas sociais de produção de uma esfera pública ampliada e efetiva.

\section{OUTRAS MODELAÇÕES DA ESFERA PÚBLICA}

Um exemplo mais efetivo de esfera pública instituinte é o orçamento participativo, uma vez que

permite que a cidadania conheça [e exercite] a estrutura de receita pública, de onde ela se origina, quem paga e quem não paga. A população, a partir de critérios deliberados coletivamente, decide onde esses recursos são gastos, quais as prioridades e quais as obras a serem feitas com eles. [...] o orçamento participativo supera a alienação, aprofunda a democracia e forma uma cidadania viva, crítica e participativa, capaz de decidir conscientemente sobre as questões que lhe dizem respeito (DUTRA, 1999).

Ultrapassando a participação e deliberação, o orçamento participativo também permite aos segmentos da população reconhecer os interesses de classe que se expressam na luta pela apropriação dos recursos públicos; interesses que, fora de tais esferas públicas, mantêm-se geralmente ocultos. Todavia, a população precisa superar alguns aspectos restritivos à deliberação popular sobre o orçamento público, porque geralmente as plenárias deliberam somente sobre a rubrica do orçamento destinado aos investimentos, que em média correspondem a 10\% do orçamento municipal, por exemplo. É necessário ampliar o limite de participação popular, de forma a tornar tal esfera mais pública do que já é, aumentando não só a autonomia da sociedade civil nesse processo, mas também sua responsabilidade.

$\mathrm{O}$ orçamento participativo pode ser igualmente um canal de ampliação da esfera pública quando, possibilitan- do à população o reconhecimento e a discussão dos problemas locais e garantindo-lhe o direito de decidir conscientemente sobre as questões que lhe dizem respeito, possibilita a visualização, o acompanhamento e o controle das ações e dos projetos sociais públicos. Somente em uma esfera pública ampliada com esse mecanismo de controle há a possibilidade de criar um programa integrado de inclusão social. Não é à toa que as propostas de orçamento participativo, tanto quanto as experiências de programas integrados de inclusão, são coordenadas diretamente pelos gabinetes dos prefeitos municipais, mas são geridas segundo modelos descentralizados e participativos. ${ }^{5}$ Atualiza-se a opção política de gestão dos governantes, fazendo os problemas chegarem diretamente ao governo, tanto quanto se facilita a tomada de direção no sentido de aderir à satisfação das necessidades públicas.

Um outro exemplo de esfera pública instituinte são os conselhos de gestão, sobretudo os municipais, cada vez mais caracterizados como modelos de gestão das políticas sociais. Sua importância está no fato de constituírem formas de descentralização das deliberações sobre as ações do governo e de coordenação das ações da sociedade civil em torno da efetivação das políticas sociais necessárias para o enfrentamento da exclusão social. Nesse sentido, os conselhos são grandes canais de interlocução entre a esfera estatal e a sociedade civil.

Desde a promulgação da Constituição de 1988 a sociedade brasileira vem reestruturando as esferas de participação popular, buscando o reordenamento das instâncias decisórias acerca das políticas sociais públicas. Em 16 anos de mudanças, porém, poucas delas já estão institucionalizadas como canais efetivos de expressão das demandas da população, o que pode ser explicado por diversos fatores e condições hoje presentes na experiência dos sujeitos envolvidos com a questão social.

Entre as esferas de participação popular e de expressão de suas demandas pela cidadania, os conselhos de gestão formam um locus privilegiado de análise, uma vez que nessa esfera explicitam-se conflitos decorrentes da convivência de concepções e formas tradicionais, hegemônicas e emergentes de controle social.

Os conselhos apresentam concepções tradicionais e hegemônicas, que ficam claras na sua forma de composição e nas suas atribuições em suas relações com o governo. Tais características são identificadas tanto na relutância de vários governantes em admitir as decisões e resoluções dos conselhos quanto no padrão tutelado que muitos governos reproduzem na manutenção dos conselhos. 
Na busca de referenciais para a ação dos conselheiros, com vistas a dinamizar procedimentos da administração pública e atender às demandas dos segmentos representados, em muitos casos confundem-se as atribuições dos conselhos com as do Estado. Tal confusão desdobra-se na fusão das estruturas de funcionamento de ambos, o que inibe o desenvolvimento de relações fiscalizadoras e reivindicatórias coerentes e eficazes.

O desconhecimento acerca do funcionamento da burocracia estatal e de suas inconsistências nas relações entre instâncias diferentes de governo tem impedido o desenvolvimento de composições pluralistas nos conselhos, uma vez que as concepções de descentralização ficam mal resolvidas. Nessa condição, os conselheiros acabam tornando-se elementos mandatários que se envolvem alternadamente nas decisões governamentais, sem exercer um poder de controle social mais efetivo na estrutura organizacional da administração pública, num sentido amplo.

Efetivados como burocracia, mas relegados à condição de apêndice nas decisões governamentais, os conselhos prestam-se a procedimentos errôneos, mesmo que suas ações busquem o bem comum.

As experiências dos conselhos dos direitos da criança e do adolescente já implantados em muitos municípios, porém, têm mostrado que eles são capazes de superar esses entraves, alcançando o status do que alguns analistas têm chamado de "o quarto poder". Embora essa denominação envolva concepções complexas acerca do exercício das ações de governo, mesmo que restrita à esfera municipal, deve-se considerar ao menos que as ações desses conselhos têm contribuído decisivamente para a reorganização de algumas estruturas da administração pública, pela ampliação de canais de vocalização dos segmentos populares que deles participam. Em alguns casos, essa ampliação coloca demandas que, quando atendidas ou negociadas, detonam um processo de cidadania em construção, que permite pensar a emergência de um "Welfare State Municipal", como indica Manzini-Covre (1996, p. 57-85).

\section{FECHANDO CIRCUITOS DE ANÁLISE}

Seguindo as reflexões anteriores, é necessário afirmar que a identificação das esferas públicas instituintes carece de uma distinção a ser feita entre os modos de objetivação e subjetivação da realidade que se operam acerca das "necessidades públicas". O discurso comum daqueles que consideram as ações de Estado como propostas homogeneizadoras, que anulam as subjetividades produzidas nas relações entre os segmentos sociais, geralmente recai na proposta de uma "sociedade de risco" (BECK, 1995), onde "o que está em risco" não são mais as próprias necessidades públicas, mas os interesses privados.

Vivemos hoje em uma sociedade de riscos diferenciados, sem dúvida, mas sua resolução não prescinde de uma esfera pública, pois é nela que as subjetividades encontram-se como elementos diferenciadores, mas ainda como códigos comuns de convivência entre sujeitos que querem exercer a cidadania.

\section{NOTAS}

Para Aldaíza Sposati.

Este artigo é uma versão revisada e ampliada da comunicação homônima apresentada no GT "Terceiro Setor: teoria e prática", no Congresso Estadual de Sociólogos do Estado de São Paulo - ASESP, realizado em outubro de 2001 na PUC (SP).

1. Nesse sentido, conferir os artigos sobre mínimos sociais publicados na revista Serviço Social \& Sociedade, números 55 e 58.

2. Termo utilizado por uma agente de ONG em São Leopoldo (RS), durante o Colóquio de Pesquisa "Município e pobreza: ações do Estado e da sociedade civil", realizado na Unisinos, em 17/05/2001: "ela não substitui as obrigações do poder público. A ONG atende seu foco de missão".

3. Os dados aqui descritos referem-se às pesquisas realizadas pelo NIPPC, para "Caracterização da rede de proteção social/assistencial" dos municípios de São José dos Campos (1996), Taubaté (1998), e Areias (2000).

4. As estratégias de ampliação e diversificação dos temas dessa campanha ambiental estão sendo comparadas, no momento, com uma semelhante realizada em Poços de Caldas (MG), promovida por outra ONG de ambientalistas. Este município apresenta características geofísicas e problemas ambientais e urbanísticos semelhantes aos de Campos do Jordão, mas as estratégias ideológicas e políticas das campanhas são diferenciadas e adequadas às relações sociais locais, buscando mais "eficácia simbólica".

5. Um caso exemplar dessa estratégia de governo é o "Programa Integrado de Inclusão Social" implantado pela Prefeitura Municipal de Santo André (SP), na gestão do prefeito Celso Daniel.

\section{REFERÊNCIAS BIBLIOGRÁFICAS}

BAPTISTA, D. et al. (Org.). Cidadania e subjetividade. São Paulo: Imaginário, 1997.

BECK, U. A sociedade do risco: a caminho de um outro moderno. Rio de Janeiro: Paz e Terra, 1995.

CAMPA, R. A época das incertezas e as transformações do Estado contemporâneo. São Paulo: Difel; Istituto Italiano di Cultura, 1985.

CASTEL, R. As metamorfoses da questão social. Uma crônica da sociedade do salariado. Petrópolis: Vozes, 1997.

DUTRA, O. Reforma tributária e participação popular. Folha de S.Paulo, São Paulo, Caderno 1:3, 21 maio 1999. 
FERNANDES, R.C. O que é o Terceiro Setor? In: IOSCHPE, E.B. (Org.). Terceiro Setor. Desenvolvimento social sustentado. 2. ed. Rio de Janeiro: GIFE; Paz e Terra, 1997.

Privado, porém público: o Terceiro Setor na América Latina. Rio de Janeiro: Relume-Dumará, 1996.

FOLHA DE S.PAULO. São Paulo, 29 abr. 2001, p. C3.

GARCÍA-PELAYO, M. Las transformaciones del Estado Contemporáneo. Madrid: Alianza Universidad, 1977.

GOHN, M. da G. Os Sem-Terra, ONGs e Cidadania. 2. ed. São Paulo: Cortez, 2000

LESSA, C.; et al. Pobreza e política social: a exclusão social nos anos 90. Praga - Estudos Marxistas, São Paulo, Hucitec, n. 3, p. 6388, 1997.

LOPES, J.R. Mínimos sociais, cidadania e assistência social. Serviço Social \& Sociedade, São Paulo, Cortez, n. 58, p. 94-108, 1998.

MANZINI-COVRE, M. No caminho de Hermes e Sherazade: cultura, cidadania e subjetividade. Taubaté: Vogal, 1996.

OLIVEIRA, F. de. Os direitos do antivalor: a economia política da hegemonia imperfeita. Petrópolis: Vozes, 1998.

PEREIRA, P.A.P. A política social no contexto da seguridade social e do Welfare State: a particularidade da assistência social. Serviço Social \& Sociedade, São Paulo, Cortez, n. 56, p. 60-76, 1998.
RAICHELIS, R. Assistência social e esfera pública: os conselhos no exercício do controle social. Serviço Social \& Sociedade, São Paulo, Cortez, n. 56, p. 77-96, 1998.

SEN, A. Desenvolvimento como liberdade. São Paulo: Cia. das Letras, 2000.

SPOSATI, A. A Constituição de 1988 e o percurso das políticas sociais públicas no Brasil. In: LOPES, J.R. (Org.). O processo de democratização na sociedade brasileira: 20 anos de luta pela cidadania. São Paulo: Sesc; Nepps-Unitau, 1999.

SILVA, J.O. Políticas de Assistência Social e gestão da pobreza. $\mathrm{Ca}$ dernos Cedope, São Leopoldo, Unisinos, n. 16, 1999. (Série Movimentos sociais e cultura).

VIEIRA, E. A Constituição de 1988 e o novo cenário político-social do Brasil. In: LOPES, J.R. (Org.). O processo de democratização na sociedade brasileira: 20 anos de luta pela cidadania. São Paulo: Sesc; Nepps-Unitau, 1999.

WILLIAMS, R. Cultura. Rio de Janeiro: Paz e Terra, 1992.

José Rogério Lopes: Pedagogo, Doutor em Ciências Sociais (PUC-SP), Professor da Universidade de Taubaté (SP). 